\title{
Stres psikologis dengan kejadian gastritis pada narapidana di sukadana, Lampung
}

\author{
Rahma Elliya ${ }^{1 *}$, Leni Haryanti ${ }^{2}$ \\ 1Program Studi IImu Keperawatan Fakultas Kedokteran Universitas Malahayati \\ *Email: bundaauliyusri@yahoo.co.id \\ 2Rutan Kelas II B Sukadana Lampung Timur
}

\begin{abstract}
Psychological stress in gastritis occurrence among prisoners at sukadana, Lampung
\end{abstract}

Background: Based on Indonesia's health profile in 2011, gastritis is one of the 10 most common diseases in hospitalized patients in Indonesia with 30,154 cases (4.9\%). Based on data from the monthly repor ts of noncommunicable diseases, it was known that in December 2018 the most common diseases were 12 people with digestive disorders followed by 2 people with respiratory diseases and 2 people with dental diseases.

Purpose: To identify psychological stress in gastritis occurrence among prisoners at sukadana, Lampung

Method: A quantitative research, analytic survey research design with cross sectional approach). The population in this study were all residents of detention in class II B Sukadana prison. Independent variable: stress. Dependent variable: gastritis availability. Collecting data with questionnaires and medical records. It is planned to be conducted in March - April 2019. Analysis of data is univariate (frequency distribution) and bivariate using the chi square test.

Results: It was known by respondents with the incidence of gastritis, as many as $130(60.5 \%)$ respondents were gastritis and as many as $85(39.5 \%)$ respondents were not gastritis. It was known by respondents with the incidence of stress, as many as $111(51.6 \%)$ respondents were stressed and as many as $104(48.4 \%)$ respondents were not stressed. There is a relationship between stress and the incidence of gastritis in prisoners ( $p$-value $=0,000 O R=9,012$ ). Suggestions provide information to respondents regarding factors that influence the incidence of gastritis, especially stress.

Conclusion: There is a relationship of Stress with the incidence of gastritis in inmates in Sukadana. Suggestions provide information to respondents regarding factors that influence the incidence of gastritis, especially stress.

\section{Keywords: Psychological stress; Gastritis occurrence; Prisoners}

Pendahuluan: Gastritis menjadi salah satu penyakit dari 10 penyakit terbanyak pada pasien inap di rumah sakit di Indonesia dengan jumlah 30.154 kasus (4,9\%). Berdasarkan data dari laporan bulanan penyakit tidak menular diketahui pada bulan Desember 2018 penyakit terbanyak adalah gangguan pencernaan sebanyak 12 orang diikuti penyakit pernapasan sebanyak 2 orang dan penyakit gigi sebanyak 2 orang.

Tujuan: Diketahui hubungan stres dengan kejadian gastritis pada narapidana di Sukadana.

Metode: Penelitian kuantitatif, rancangan penelitian survei analitik dengan pendekatan cross sectional). Populasi dalam penelitian adalah seluruh penghuni rumah tahanan di lapas kelas II B Sukadana . Variabel independen: stress. Variabel dependen: kejadian gastritis. Pengumpulan data dengan kuesioner dan rekam medik. Telah dilakukan pada bulan Maret - April 2019. Analisa data secara univariat (distribusi frekuensi) dan bivariat menggunakan uji chi square.

Hasil: Diketahui responden dengan kejadian gastritis, sebanyak $130(60,5 \%)$ responden gastritis dan sebanyak $85(39,5 \%)$ responden tidak gastritis. Diketahui responden dengan kejadian stress, sebanyak $111(51,6 \%)$ responden stres dan sebanyak $104(48,4 \%)$ responden tidak stress. Ada hubungan antara stres dengan kejadian gastritis pada narapidana ( $p$-value $=0,000 \mathrm{OR}=9,012$ ).

Simpulan: Ada hubungan Stres dengan kejadian gastritis pada narapidana di rumah tahanan Negara klas II B Sukadana. Saran memberikan informasi kepada responden terkait faktor yang mempengaruhi kejadian gastritis khususnya stres.

Kata Kunci: Stress; Gastritis; Narapidana 


\section{PENDAHULUAN}

Insiden gastritis di dunia sekitar 1,8-2,1 juta dari jumlah penduduk setiap tahunnya, di Inggris $(22 \%)$, China $(31 \%)$, Jepang $(14,5 \%)$, Kanada (35\%), dan perancis $(29,5 \%)$. Insiden terjadinya gastritis di Asia Tenggara sekitar 583.635 dari jumlah penduduk setiap tahunnya (World Health Organization, 2010; (Khusna, Fahrun, \& Faizah, 2016; Tina, \& Takdir, 2019).

Setiap tahunnya di Indonesia angka kejadian gastritis cukup tinggi dengan prevalensi 274,396 kasus dari 238.452.952 jiwa penduduk atau sebesar 40,8\%. Gastritis menjadi salah satu penyakit dari 10 penyakit terbanyak pada pasien inap di rumah sakit di Indonesia dengan jumlah 30.154 kasus $(4,9 \%)$ (Tina, \& Takdir, 2019).

Bahaya penyakit gastritis jika dibiarkan terus menerus akan merusak fungsi lambung dan dapat meningkatkan risiko untuk terkena kanker lambung hingga menyebabkan kematian (Saydam, 2011). Banyak faktor yang merupakan pemicu terjadinya gastritis yaitu pola makan, stress, kopi, frekuensi makan, makanan pedas, keteraturan makan, alkohol, terlamat makan, usia, penggunaan obat anti inflamasi non steroid. Penyakit gastritis yang diakibatkan oleh produksi asam lambung yang berlebihan dapat diperparah oleh faktor-faktor yang menyebabkan kekambuhan gastritis. Biasanya waktu makan yang tidak teratur, gizi atau kualitas makanan yang kurang baik, jumlah makanan terlalu banyak atau bahkan terlalu sedikit (Irianto, 2016).

Gastritis biasanya terjadi ketika terlalu banyak makan jenis makanan yang pedas dan asam serta pola makan yang tidak teratur, stres juga dapat menyebabkan penyakit gastritis (Tamsuri, \& Setiawan, 2017). Stres memiliki efek negatif melalui mekanisme neuroendokrin (peningkatan hormon kortisol yang menyebabkan aktivitas sekresi lambung (peptin dan $\mathrm{HCL}$ ) terhadap saluran pencernaan sehingga beresiko untuk mengalami gastritis (Price, \& Wilson, 2012). Stres terjadinya ketegangan ketika seseorang mendapatkan masalah atau tantangan dan seseorang tersebut belum mampu menemukan jalan keluarnya, bisa jadi dikarenakan banyak pikiran lain yang menganggu ketika ia memulai berpikir mencari solusinya, disini terdapat ketidakseimbangan antara tuntutan dan kemampuan untuk mengatasinya (Broto, 2016).
Faktor presdiposisi dalam munculnya kekambuhan gastritis dari penelitian yang dilakukan antara lain adalah karakteristik responden, stres psikologis, dan perilaku konsumsi (Rahmawati, 2011), penelitian tersebut sejalan dengan penelitian yang mengungkapkan terdapat hubungan stres dengan kejadian gastritis, dimana semakin tinggi tingkat stres maka semakin rentan terkena gastritis (Prasetio, 2014).

Penelitian ini juga didukung oleh penelitian terdahulu yang mengungkapkan ada hubungan yang signifikan antara stres dengan kejadian gastritis pada remaja (Saroinsong, Palandeng, \& Bidjuni, 2014). Beberapa penelitiannya juga menunjukkan bahwa ada hubungan stres terhadap kekambuhan gastritis, penyakit gastritis salah satu penyakit psikomatik yang salah satu penyebabnya adalah stress (Atmaja, 2011; Rahmawati, 2011; Handayani, 2012).

Diketahui bahwa jumlah napi terbanyak ada di Lapas kelas I Bandar Lampung berjumlah 1080, dengan kapasitas sebesar 620 orang sehingga memiliki kelebihan kapasitas sebesar $74 \%$, dan terendah di rutan kelas IIB Krui berjumlah 160 orang dengan kapasitas sebesar 100 orang sehingga memiliki kelebihan kapasitas sebesar $60 \%$, dan di Rutan kelas II B Sukadana berjumlah 467 dengan kapasitas kapasitas sebesar 155 orang sehingga memiliki kelebihan kapasitas sebesar $201 \%$. Berdasarkan data terlihat bahwa kapasitas rutan di Lapas II B Sukadana dengan kepadatan hunian tinggi. Berdasarkan data 2017 angka kejadian gastritis berjumlah 48 penderita, dan pada tahun 2018 angka kejadia gastritisis berjumlah 62 penderita, dari laporan bulanan penyakit tidak menular diketahui pada bulan Desember 2018 penyakit terbanyak adalah gangguan pencernaan sebanyak 12 orang diikuti penyakit pernapasan sebanyak 2 orang dan penyakit gigi sebanyak 2 orang. Berdasarkan hasil prasurvey, Mei 2019 diketahui bahwa dari 10 orang narapidana yang pernah mengalami gastritis menurut diagnosa dokter dimana dari 10 orang tersebut, sebanyak $70 \%$ mengungkapkan bahwa sering merasa mereka sering menjadi mudah marah, dan agresi, tidak dapat relaks, apalagi karena jumlah penghuni rutan yang sangat padat membuat mereka semkin merasa tertekan. Sebanyak 30\% mengungkapkan susah tidur, sering gelisah.

Rahma Elliya** Program Studi llmu Keperawatan Fakultas Kedokteran Universitas Malahayati.

${ }^{*}$ Email: bundaauliyusri@yahoo.co.id

Leni Haryanti ${ }^{2}$ Rutan Kelas II B Sukadana Lampung Timur 
Peneliti mengambil penyakit gastritis karena kejadian penyakit gastritis mengalami peningkatan setiap tahun, selain itu kondisi lapas dengan kepadatan yang melebihi kapasitas dapat menimbulkan permasalahan sendiri bagi kejiwaan penghuni lapas, selain itu adanya perbedaan kehidupan antara di dalam rumah tahanan dan diluar rumah tahanan salah satunya adalah kebebasan, atau hak sosialisasi kepada teman, keluarga dan lain-lain, sehingga ada kebiasan yang hilang yang dapat menyebabkan gangguan psikologis pada penghuni rumah tahanan.

\section{METODE PENELITIAN}

Jenis penelitian kuantitatif dengan rancangan analitik dan pendekatan cross sectional, sudah lulus kelaikan etik dari Komisi Etik Penelitian Kesehatan Universitas Malahayati dengan nomor surat keterangan kelaikan etik 325/EC/KEPUNMAL//2019 pada tanggal 22 Mei 2019. Penelitian telah dilaksanakan di Rumah Tahanan Negara klas II B Sukadana Kabupaten Lampung Timur pada Maret-Juli 2019. Populasi seluruh penghuni rumah tahanan di lapas dan jumlah sampel sebanyak 215 responden. Teknik sampling secara non probability sampling. Pengumpulan data dengan kuesioner dan rekam medik. Analisa data secara univariat (distribusi frekuensi) dan bivariat menggunakan uji chi square.

Untuk mengukur gastritis dilakukan pengukuran langsung kepada responden menggunakan rekam medis dan lembar observasi yang telah disediakan oleh peneliti. Untuk mengetahui stres peneliti melakukan pengukuran langsung dengan mengisi kuesioner DASS(Depression Anxiety and Stress Scale). Kuesioner ini terdiri dari 14 pernyataan yang mungkin sesuai dengan pengalaman responden dalam menghadapi situasi hidup seharihari. Terdapat empat pilihan jawaban yang disediakan untuk setiap pernyataan yaitu: $0=$ Tidak sesuai dengan saya sama sekali, atau tidak pernah; 1 = Sesuai dengan saya sampai tingkat tertentu, atau kadang-kadang; 2 = Sesuai dengan saya sampai batas yang dapat dipertimbangkan, atau lumayan sering; 3 = Sangat sesuai dengan saya, atau sering sekali.Skor miimal 0 skor maksimal 42 (Lovibond S, 1995). Selanjutnya, responden diminta untuk menjawab pengalaman responden selama satu minggu belakangan ini.

\section{HASIL}

Tabel. 1. Karakteristik Demografi Responden N=215

\begin{tabular}{llccc}
\hline Demografi & & $\mathbf{n}$ & $\%$ & $\mathbf{M}$ (SD) \\
& & & & $36.40 \pm 9.372$ \\
Usia (Tahun)(Rentang: 24-50) & & 215 & & $1.19 \pm 1.137$ \\
Lamanya sakit (Tahun)(Rentang: 0-3) & & 212 & & \\
Jenis Kelamin & Laki-Laki & 141 & 65.6 & \\
& Perempuan & 74 & 34.4 & \\
Gastritis & Gastritis & 130 & 60.5 & \\
& Tidak Gastritis & 85 & 39.5 \\
Stres & & & \\
& Stres & 111 & 51.6 & \\
& Tidak stres & 104 & 48.4 & \\
\hline
\end{tabular}

Berdasarkan tabel 1. diketahui bahwa responden berusia antara 24 tahun sampai dengan 50 tahun dengan mean sebesar 36.40 dan standar deviasi 9.372. Tahun lamanya sakit antara 0 tahun sampai 3 tahun dengan mean sebesar 1.19 dan standar deviasi 1.137. Jenis kelamin penderita sebagian besar adalah laki-laki sebanyak 141 responden (65.6\%). Diketahui dari 215 responden dengan kejadian gastritis, sebanyak 130 (60.5\%) responden gastritis dan sebanyak $85(39.5 \%)$ responden tidak gastritis. Responden dengan kejadian stres, sebanyak $111(51.6 \%)$ responden mengalami stres dan sebanyak $104(48.4 \%)$ responden tidak stres.

Rahma Elliya* Program Studi llmu Keperawatan Fakultas Kedokteran Universitas Malahayati.

*Email: bundaauliyusri@yahoo.co.id

Leni Haryanti ${ }^{2}$ Rutan Kelas II B Sukadana Lampung Timur 
Tabel 2. Hubungan Stres Dengan Kejadian Gastritis Pada Narapidana N=215

\begin{tabular}{|c|c|c|c|c|c|c|c|c|}
\hline \multirow{3}{*}{ Stres } & \multicolumn{4}{|c|}{ Gastritis } & \multirow{3}{*}{$\mathbf{N}$} & \multirow{3}{*}{$\%$} & \multirow{3}{*}{$p$-value } & \multirow{3}{*}{$\begin{array}{c}\text { OR } \\
\text { Cl } 95 \%\end{array}$} \\
\hline & \multicolumn{2}{|c|}{ Gastritis } & \multicolumn{2}{|c|}{ Tidak Gastritis } & & & & \\
\hline & $\mathrm{n}$ & $\%$ & $\mathrm{n}$ & $\%$ & & & & \\
\hline Stres & 93 & 43.2 & 18 & 8.4 & 111 & 51.6 & & 9.356 \\
\hline Tidak stres & 37 & 17.2 & 67 & 31.2 & 104 & 48.4 & 0,000 & $(4.909-17.830)$ \\
\hline Total & 130 & 60.4 & 85 & 39.6 & 215 & 100.0 & & \\
\hline
\end{tabular}

Berdasarkan Tabel 2. dapat diketahui dari 111 responden yang stres sebanyak $93(43.2 \%)$ responden mengalami gastritis dan sebanyak $18(8.4 \%)$ responden tidak mengalami gastritis dan dari 104 responden yang tidak stres sebanyak $37(17.2 \%)$ responden mengalami gastritis dan sebanyak $67(31.2 \%)$ responden tidak gastritis.

Hasil uji statistik diperoleh $p$-value $=0,000$ yang berarti $<a(0,05)$, maka dapat disimpulkan bahwa ada Hubungan antara stres dengan kejadian gastritis pada narapidana dengan nilai OR 9,356 berarti responden yang stres memiliki risiko 9 kali lebih besar terjadi gastritis jika dibandingkan dengan responden yang tidak stress.

\section{PEMBAHASAN}

\section{Distribusi Frekuensi Kejadian Gastritis Pada} Narapidana

Berdasarkan hasil penelitian dari 215 responden dengan kejadian gastritis, sebanyak $130(60.4 \%)$ responden gastritis dan sebanyak 85 $(39.6 \%)$ responden tidak gastritis.

Gastritis yang kerap juga disebut radang lambung dapat menyerang setiap orang dengan segala usia. Ada sejumlah gejala yang biasa dirasakan penderita sakit gastritis seperti mual, perut terasa nyeri, perih (kembung dan sesak) pada bagian atas perut (ulu hati). Biasanya, nafsu makan menurun secara drastis, wajah pucat, suhu badan naik, keluar keringat dingin, dan sering bersendawa terutama dalam keadaan lapar (Puri, \& Suyanto, 2016).

Gastritis salah satu masalah kesehatan saluran pencernaan yang paling sering terjadi. Gastritis lambung merupakan gangguan umum diskontinuitas dari mukosa lambung, yang disebabkan oleh berbagai faktor seperti alkohol, stres, obat antiinflamasi, dan lain-lain. Penderita gastritis umumnya mengalami gangguan pada saluran pencernaan atas, berupa nafsu makan menurun, perut kembung dan perasaan penuh di perut, mual, muntah, dan bersendawa (Saroinsong, Palandeng, \& Bidjuni, 2014).

Membran mukosa lambung menjadi edema dan hiperemik (kongesti dengan jaringan, cairan, dan darah) dan mengalami erosi superfisial, bagian ini mensekresi sejumlah getah lambung, yang mengandung sangat sedikit asam tetapi banyak mukus. Ulserasi superfisial dapat terjadi dan dapat menimbulkan hemoragi. Pasien dapat mengalami ketidaknyamanan, sakit kepala, malas, mual, dan anoreksia, sering disertai dengan muntah dan cegukan. Beberapa pasien, asimtomatik. Mukosa lambung mampu memperbaiki diri sendiri setelah mengalami gastritis. Kadang-kadang, hemoragi memerlukan intervensi bedah. Bila makanan pengiritasi tidak dimuntahkan tetapi mencapai usus, dapat mengakibatkan kolik dan diare. Biasanya, pasien sembuh kira-kira sehari, meskipun napsu makan mungkin menurun selama 2 atau 3 hari kemudian (Smeltzer, \& Bare, 2009).

Dalam penelitian sebelumnya terdapat hubungan antara penyakit gastritis dengan keteraturan makan, frekuensi makan, kebiasaan makan pedas, kebiasaan makan asam, dan frekuensi minuman iritatif. Selain itu stress juga merupakan pemicu terjadinya gastritis tersebut (Hartati, \& Cahyaningsih, 2016; Merita, Sapitri, \& Sukandar, 2018).

Menurut Peneliti, gastritis disebabkan oleh banyak hal, diantaranya faktor fisik dan psikis. Faktor langsung pada penderita gastritis diakibatkan oleh ketidakteraturan diet, misalnya makan terlalu banyak dan cepat atau makan makanan yang terlalu berbumbu, keteraturan makan, frekuensi makan, kebiasaan makan pedas, kebiasaan makan asam, dan frekuensi minuman iritatif merupakan salah satu pemicu terjadinya gastritis. Selain itu gastritis merupakan suatu penyakit dengan kekambuhan, kekambuhan gastritis dapat terjadi dengan faktor munculnya

Rahma Elliya ${ }^{\text {** }}$ Program Studi llmu Keperawatan Fakultas Kedokteran Universitas Malahayati.

*Email: bundaauliyusri@yahoo.co.id

Leni Haryanti ${ }^{2}$ Rutan Kelas II B Sukadana Lampung Timur 
karakteristik responden, stres psikologis, perilaku makan dan minum.

Peneliti berpendapat gastritis dapat dilakukan pencegahan agar tidak terjadi kekambuhan, di antaranya adalah pola makan yang sudah baik yaitu makan dalam jumlah kecil tapi sering serta memperbanyak makan makanan yang mengandung tepung, seperti nasi, jagung, dan roti akan menormalkan produksi asam lambung. Mengurangi makanan yang dapat mengiritasi lambung, misalkan makanan yang pedas, asam, dogoreng, dan berlemak.

\section{Distribusi Frekuensi Stres Pada Narapidana}

Berdasarkan hasil penelitian dari 215 responden dengan kejadian stress, sebanyak 111 $(51.6 \%)$ responden stres dan sebanyak 104 $(48.4 \%)$ responden tidak stress.

Stres stimulus yang menimbulkan distres dan menciptakan tuntutan fisik dan psikis pada seseorang. Stres membutuhkan koping dan adaptasi. Sindrom adaptasi umum atau teori Selye, menggambarkan stres sebagai kerusakan yang terjadi pada tubuh tanpa mempedulikan apakah penyebab stres tersebut positif atau negatif. Respons tubuh dapat diprediksi tanpa memperhatikan stresor atau penyebab tertentu (Mumpuni, \& Wulandari, 2010).

Hasil penelitian sebelumnya menunjukkan bahwa mayoritas responden dengan stres pada tingkat sedang yaitu sebanyak 28 orang $(40.0 \%)$ (Husada, 2015). Penelitian lainnya diperoleh informasi faktor stres yang berisiko terjadinya gastritis sebanyak 28 responden $(70 \%)$ dan tidak berisiko sebanyak 12 responden $(30 \%)$ dari total 40 responden (Dewi, 2014).

Menurut peneliti stress terjadi karena beban yang menarik seseorang dari segala penjuru, tekanan yang dirasakan pada saat menghadapi tuntutan atau harapan yang menantang kemampuan seseorang untuk mengatasi atau mengelola hidup. Maka perlu adanya strategi dalam menghadapi stres agar seseorang mampu melanjutkan hidupnya dengan sehat. Ketika individu mengalami stres seringkali tidak memiliki kemampuan mengatasi atau melakukan strategi dengan tepat, sehingga permasalahan yang dihadapi tidak mampu diselesaikannya. Stres yang terjadi dapat memicu timbulnya stres yang berhubungan dengan maupun psikologis, dalam tingkat keparahan tinggi dapat menekan tingkat ketahanan tubuh, bahkan tragisnya bisa sampai pada tindakan brutal (anarkis) atau nekat bunuh diri. Stres yang melebihi tahap tertentu apabila tidak dikelola dengan sebaik-baiknya akan menimbulkan berbagai masalah. Upaya dalam mengatasi stress yang terjadi salah satunya dengan berfikir positif, berpikir positif adalah aplikasi langsung yang praktis dari teknik spiritual untuk mengatasi kekalahan dan memenangkan kepercayaan serta menciptakan suasana yang menguntungkan bagi perkembangan hasil yang positif. Selain berfikir positif seseorang juga dapat lebih mendekatkan diri kepada sang pencipta dan terus berdoa sesuai keyakinan.

\section{Hubungan Antara Stress Dengan Kejadian Gastritis Pada Narapidana}

Hasil uji statistik diperoleh $p$-value $=0,000$ yang berarti $<a(0,05)$, maka dapat disimpulkan bahwa ada Hubungan antara stres dengan kejadian gastritis pada narapidana dengan nilai OR 9,012 berarti responden yang stress memiliki risiko 9 kali lebih besar terjadi gastritis jika dibandingkan dengan responden yang tidak stress.

Faktor utama terjadinya gastritis dan merupakan faktor yang menyebabkan kekambuhan penyakit gastritis adalah stress. Orang yang mengalami stres seringkali mengalami gangguan pada sistem pencernaannya, misalnya pada lambung terasa kembung mual dan pedih hal ini disebabkan karena asam lambung yang berlebihan (hipercidity). Dalam istilah kedokteran disebut dengan gastritis atau dalam bahasa awam disebut dengan maag. Gastritis dapat menyerang pada narapidana karena pada narapida terdapat aturan - aturan dan adanya beberapa larangan yang tidak boleh dilakukan oleh narapidana sehingga dengan aturan-aturan tersebut menyebabkan penghuni rumah tahanan tidak merasakan kebebasan yang pada akhirnya membawa perubahan psikologi dirinya yang menyebabkan stress. Rangsangan emosional yang kuat dapat menyebabkan terjadinya peningkatan sekresi asam lambung $\geq 50 \mathrm{ml} / \mathrm{jam}$. Kadar $\mathrm{HCl}$ yang meningkat dapat mengiritasi mukosa lambung dan ini dapat menyebabkan terjadinya gastritis. Kekambuhan pada penderita gastritis salah satunya dapat dipengaruhi oleh stres psikologis dimana akan terjadi peningkatan sekresi asam lambung yang dapat mengiritasi mukosa lambung kembali. Situasi stres mengaktivasi

Rahma Elliya"* Program Studi llmu Keperawatan Fakultas Kedokteran Universitas Malahayati.

*Email: bundaauliyusri@yahoo.co.id

Leni Haryanti ${ }^{2}$ Rutan Kelas II B Sukadana Lampung Timur 
hipotalamus yang selanjutnya mengendalikan dua sistem neuroendokrin, yaitu sistem simpatis dan sistem korteks adrenal (Mumpuni, \& Wulandari, 2010).

Sistem saraf simpatik berespons terhadap impuls saraf dan hipotalamus (Hawari, 2013). Salah satunya hormon ACTH (adrenocorticotropic) yang dibawa melalui aliran darah ke korteks adrenal dan Menstimulasi pelepasan sekelompok hormon, termasuk kortisol (Asdie, Wiyono, Rahardjo, Triwibowo, \& Danawati, 2012). Peningkatan hormon kortisol menyebabkan aktivitas sekresi lambung (peptin dan hidroklorida $(\mathrm{HCL})$ ) sehingga beresiko untuk mengalami gastritis (Price, \& Wilson, 2012).

Faktor utama terjadinya gastritis dan merupakan faktor yang menyebabkan kekambuhan penyakit gastritis adalah stres. Penelitian Wolf juga mendukung pernyataan tersebut dengan mengemukakan bahwa efek stres pada saluran pencernaan antara lain menurunkan saliva sehingga mulut menjadi kering, menyebabkan kontraksi yang tidak terkontrol pada otot esophagus sehingga menyebabkan sulit untuk menelan, peningkatan asam lambung (Saroinsong, Palandeng, \& Bidjuni, 2014).

Hasil uji statistik penelitian sebelumnya menggunakan chi-square, ditemukan nilai $\rho$ value $=0.004<a 0,05$, yang artinya ada hubungan yang bermakna antara depresi dengan lama masa tahanan narapidana (Tololiu, \& Makalalag, 2015). Hasil penelitian lain menunjukkan bahwa mayoritas responden dengan stres pada tingkat sedang yaitu sebanyak 28 orang $(40,0 \%)$, responden menderita gastritis sebanyak 39 orang $(44,3 \%)$ dan ada hubungan antara stres dengan kejadian gastritis ( $2=20,93)$ dan secara statistik signifikan $(p=0,000$ $<0,05$ ), dimana semakin tinggi tingkat stres maka semakin rentan terkena gastritis (Husada, 2015).

Hasil penelitian lain menunjukkan bahwa untuk tingkat stres, $12,7 \%$ termasuk dalam kategori tingkat stres berat, $73,2 \%$ kategori tingkat stres sedang, dan 14,0\% kategori tingkat stres ringan. Sedangkan untuk gejala gangguan pencernaan, $23,6 \%$ termasuk dalam kategori gejala gastrointestinal parah, 52,9\% kategori sedang, dan $23,6 \%$ kategori ringan. Ada keterkaitan yang kuat antara tingkat stres dengan gejala gangguan gastrointestinal pada siswa perempuan ( $p=0,000$, $r=0,68)($ Nikmah, 2015).
Berdasarkan hasil penelitian diketahui bahwa dari 111 responden yang stres sebanyak 93 $(83,8 \%)$ responden mengalami gastritis hal ini sejalan dengan teori yang mengungkapkan bahwa berbagai masalah psikologik dan sosial akan muncul pada penghuni rumah tahanan. Seiring bertambah lamanya masa tahanan, hilangnya kebebasan pada penghuni rumah tahanan menyebabkan narapidana mengalami stress kondisi inilah yang menyebabkan gastritis lebih sering terjadi dan sebanyak $18(16,4 \%)$ responden tidak mengalami gastritis hal ini karena narapidana memiliki mekasine koping yang positif terhadap stres yang dihadapi seperti, mengikuti kegiatan yang diadakan oleh petugas lapas, berbincang dengan kawan atau berolahraga atau kegiatan lain yang memang di fasilitasi oleh lembaga pemasyarakatan sehingga tidak mengalami dampak negatif karena stress dan stress dapat berkurang karena kegiatan tersebut.

Hasil penelitian 111 responden yang stres sebanyak $93(83,8 \%)$ responden mengalami gastritis dan sebanyak $18(16,2 \%)$ responden tidak mengalami gastritis. Respon tubuh terhadap kesehatan mental emosional (stress) adalah keluarnya hormone-hormon dan neurontransmitter, diantarannya yang paling dominan dalah pengeluaran adrenalis dan non adrenalin. Selain itu kesehatan mental emosional juga mengeluarkan hormone adeno kortikotropok, kortisol, aldosteron, vasopressin dan thyproid stimulating hormone. Apabila substansi-substansi ini meningkat di dalam tubuh, maka denyut jantung akan bertambah cepat dan kuat, pembuluh darah mengadakan vasokonstriksi, kolesterol darah meningkat, guladarah meningkat, sel-sel darah cenderung bergumpal sehingga dapat mengakibatkan pola makan yang lebih banyak dari narapidana lainnya. Intake makan yang mencukupi dan teratur dapat menjaga kesehatan tubuh khususnya lambung tidak terkena gastritis.

Berdasarkan hasil penelitian dari 104 responden yang tidak stres sebanyak $37(35,6 \%)$ responden mengalami gastritis dan sebanyak 67 $(64,4 \%)$ responden tidak gastritis. responden mengalami gastritis hal ini dapat terjadi karena stres bukan merupakan satu-satunya faktor yang menyebabkan gastritis, masih banyak faktor lain yang tidak diambil dalam penelitian ini seperti pola makan narapidana sehingga walaupun narapidana tidak stres namun karena adanya faktor lain maka

Rahma Elliya"* Program Studi llmu Keperawatan Fakultas Kedokteran Universitas Malahayati.

*Email: bundaauliyusri@yahoo.co.id

Leni Haryanti ${ }^{2}$ Rutan Kelas II B Sukadana Lampung Timur 
narapidana mengalami gastritis. Menurut pendapat peneliti kebiasaan orang dalam mengkonsumsi makanan berbeda - beda sehingga terkadang makanan yang ada di lapas tidak sesuai dengan selera penghuni lapas sehingga penghuni lapas tidak makan atau jarang makan.

Menjalani kehidupan sebagai narapidana di Lembaga Pemasyarakatan bukan merupakan sesuatu yang menyenangkan. Individu dituntut melakukan penyesuaian terhadap kehidupan di dalam Lembaga Pemasyarakatan. Penyesuaian yang dilakukan terhadap kehidupan narapidana membutuhkan variabel waktu. Situasi lingkungan yang terpaksa harus didapat, dibedakan atas lingkungan fisik maupun sosial. Lingkungan fisik adalah semua benda mati yang ada di sekeliling narapidana, misalnya ruangan sel, bangunan penjara dan pagar penjara. Sedangkan lingkungan sosial terdiri dari teman satu sel, sipir, tukang kebun, tim medis penjara, juru masak, dan rohaniawan. Selama berada di Lembaga Pemasyarakatan, ruang gerak narapidana dibatasi dan mereka terisolasi dari masyarakat. Keadaan seperti ini dapat menjadi stressor yang menyebabkan stres pada narapidana.

Peneliti berpendapat bahwa stres yang dirasakan oleh individu yang menimbulkan upaya untuk melakukan reaksi terhadap stres yang dialaminya. Reaksi tersebut merupakan suatu aktivitas untuk melakukan penyesuaian diri terhadap situasi perangsang tertentu, yang apabila tidak dapat dilakukan dengan baik akan menyebabkan gangguan fisik maupun kejiwaan. Kondisi stres adalah suatu bentuk tanggapan seseorang, baik fisik maupun mental terhadap suatu perubahan di lingkungan yang dirasakan mengganggu dan mengakibatkan dirinya terancam.

Menurut pendapat peneliti, pada narapidana, terjadi stress dapat di sebabkan oleh banyak faktor seperti faktor psikologi pada narapidana, yang disebabkan perubahan lingkungan. Gastritis yang terjadi dapat mengakibatkan penurunan kondisi fisik/biologis, serta perubahan kondisi sosial. mental, maupun sosial ekonomi. Selain itu kurang memperhatikan jenis makanan dan minuman yang memicu terjadinya penyakit Gastritis.

Menurut peneliti Lembaga Pemasyarakatan dapat memberikan pelayanan seperti tenaga professional untuk membantu memecahkan permasalahan narapidana berkaitan dengan keadaan psikologisnya, misalnya seorang psikolog yang berwenang seperti psikolog kriminal atau psikolog sosial. Narapidana banyak mengalami kesulitan adaptasi terhadap lingkungan sosial yang memicu munculnya perilaku negatif, seperti pertengkaran antar narapidana. Pihak Lembaga Pemasyarakatan juga disarankan agar bekerjasama dengan institusi psikologi untuk mengadakan pelatihan pengelolaan stres bagi para narapidana, agar mereka tidak mengalami distres bahkan jika mungkin menumbuhkan kesadaran pribadi untuk enggan dan merasa malu atau berdosa jika berbuat kejahatan.

\section{SIMPULAN}

Diketahui responden dengan kejadian gastritis, sebanyak $130(60,5 \%)$ responden gastritis dan sebanyak $85(39,5 \%)$ responden tidak gastritis. Diketahui responden dengan kejadian stress, sebanyak $111(51,6 \%)$ responden stres dan sebanyak 104 (48,4\%) responden tidak stress. Ada hubungan antara stres dengan kejadian gastritis pada narapidana di Sukadana ( $p$-value $=0,000$ OR $=9,356$ ).

\section{SARAN}

Perlunya memberikan dukungan kepada narapidana untuk memiliki mekanisme koping yang positif dalam menghadapi stress dengan mengadakan pengajian rutin 1 minggu sekali, bercocok tanam, olahraga, Pihak Lembaga Pemasyarakatan juga disarankan agar bekerjasama dengan institusi psikologi untuk mengadakan pelatihan pengelolaan stres bagi para narapidana dalam menghadapi stress ang dialami.

\section{DAFTAR PUSTAKA}

Asdie, A. H., Wiyono, P., Rahardjo, P., Triwibowo, M. S., \& Danawati, W. (2012). Harrison prinsipprinsip ilmu penyakit dalam, edisi ke13. Jakarta: EGC.

Atmaja, F. (2011). Faktor-faktor yang mempengaruhi kekambuhan penyakit gastritis di Puskesmas Kebumen II. Gombong : STIKES Muhammadiyah Gombong.

Broto, H. D. F. C. (2016). Stress pada mahasiswa penulis skripsi. Jurnal Bimbingan dan Konseling Universitas Sanata Dharma.

Rahma Elliya'* Program Studi llmu Keperawatan Fakultas Kedokteran Universitas Malahayati.

*Email: bundaauliyusri@yahoo.co.id

Leni Haryanti ${ }^{2}$ Rutan Kelas II B Sukadana Lampung Timur 
Dewi, I. (2014). Faktor-faktor yang mempengaruhi terjadinya gastritis di wilayah kerja Puskesmas Tamalanrea Makassar. Jurnal IImiah Kesehatan Diagnosis, 4(1), 100-106.

Handayani, S. D. (2012). Hubungan dukungan keluarga dengan kekambuhan pasien Gastritis di Puskesmas Jatinangor. Students eJournal, 1(1), 28.

Hartati, S., \& Cahyaningsih, E. (2016). Hubungan perilaku makan dengan kejadian gastritis pada mahasiswa AKPER Manggala Husada Jakarta Tahun 2013. Jurnal Keperawatan, 6(1).

Hawari, D. (2013). Manajemen stres cemas dan depresi cetakan ke-4. Jakarta: FKUI.

Husada, S. K. (2015). Hubungan antara stres dengan kejadian gastritis di klinik dhanang husada sukoharjo.

Irianto, K. (2016). Epidemiologi penyakit menular dan tidak menular panduan klinis. Bandung: Alfabeta.

Khusna, L. U., Fahrun N. S. K., \& Faizah B. R. (2016). Hubungan Tingkat Pengetahuan Dengan Upaya Pencegahan Kekambuhan Gastritis Di Wilayah Kerja Puskesmas Gatak Sukoharjo (Doctoral dissertation, Universitas Muhammadiyah Surakarta).

Merita, M., Sapitri, W. I., \& Sukandar, I. (2018). Hubungan tingkat stress dan pola konsumsi dengan kejadian gastritis di Puskesmas Pakuan Baru Jambi. Jurnal Akademika Baiturrahim Jambi, 5(1), 51-58.

Mumpuni, Y., \& Wulandari, A. (2010). Cara jitu mengatasi stres. Yogyakarta. Andi Offset.

Nikmah, M. (2015). Hubungan tingkat stres dengan gejala gangguan pencernaan pada santriwati Pondok Pesantren Sirojul Mukhlasin II Payaman Magelang Tahun 2015.
Prasetio, D. (2014). Hubungan antara stress dengan kejadian gastritis di Klinik Dhanang Husada Sukoharjo.

Price. S.A \& Wilson L.M. (2012). Patofisiologi: konsep klinis proses-proses penyakit. Jakarta: EGC.

Puri, A., \& Suyanto, S. (2016). Hubungan faktor stres dengan kejadian gastritis pada mahasiswa Poltekkes Kemenkes Tanjung Karang. Jurnal IImiah Keperawatan Sai Betik, 8(1), 66-71.

Rahmawati. (2011). Hubungan antara karakteristik responden, stres psikologis, perilaku makan dan minum dengan kekambuhan penyakit gastritis di Puskesmas Kecamatan Lamongan Tahun 2010. Surabaya : Fakultas Kesehatan Masyarakat Universitas Airlangga

Saroinsong, M., Palandeng, H., \& Bidjuni, $H$. (2014). Hubungan Stres Dengan Kejadian Gastritis Pada Remaja Kelas XI IPA Di SMA Negeri 9 Manado. Jurnal Keperawatan, 2(2).

Saydam, G. (2011). Memahami Berbagai Penyakit. Bandung: Alfabeta.

Smeltzer, S. C., \& Bare, B. G. (2009). Buku ajar keperawatan medikal bedah. Jakarta: EGC.

Tamsuri, A., \& Setiawan, A. (2017). Hubungan pengetahuan tentang gastritis dengan sikap diet pada penderita gastritis. Jurnal Akp, 5(1).

Tina, L., \& Takdir, R. K. (2019). Hubungan stres, keteraturan makan, jenis makanan dengan kejadian gastritis pada santri di Pondok Pesantren Ummusabri Kota Kendari Tahun 2017. Preventif Journal, 3(2).

Tololiu, T. A., \& Makalalag, S. H. (2015). Hubungan depresi dengan lama masa tahanan narapidana di Rumah Tahanan Negara Kelas Ila Malendeng Manado. JUIPERDO-Jurnal IImiah Perawat Manado, 4(1), 14-15.

World Health Organization. (2010). World health statistics 2010. World Health Organization.

Rahma Elliya ${ }^{\text {** }}$ Program Studi llmu Keperawatan Fakultas Kedokteran Universitas Malahayati.

*Email: bundaauliyusri@yahoo.co.id

Leni Haryanti ${ }^{2}$ Rutan Kelas II B Sukadana Lampung Timur 